\title{
Invasive Plant species (Weed) Challenge in Conservation in Australia
}

\section{Rukshana Sultana* \\ Faculty of Science and Engineering, Environmental Sciences, Macquarie University, Sydney, Australia}

*Corresponding author: Faculty of Science and Engineering, Environmental Sciences, Macquarie University, Sydney, Australia, Tel: +61 415862789 , E-mail: rukshana.sultana23@gmail.com

Received Date: June 15, 2018; Accepted Date: August 13, 2018; Published Date: August 21, 2018

Copyright: $\odot 2018$ Sultana R. This is an open-access article distributed under the terms of the Creative Commons Attribution License, which permits unrestricted use, distribution, and reproduction in any medium, provided the original author and source are credited.

\begin{abstract}
Invasive plants are a nuisance to native ecosystem in Australia causing environmental degradation. Once purposely introduced plant species to the landscape for horticulture and agriculture. Nearly $10 \%$ of this naturalized pool of species has become serious invaders now with the capacity to supersede native vegetation. This exotic invasion coupled with anthropogenic climate change has aggravated the natural ecosystem setting. Several management strategies and legislative measures to minimize the impact on native biodiversity were also examined with some suggestions added for weed management.
\end{abstract}

Keywords: Conservation; Plants; Biological diversity; Native diversity

\section{Introduction}

Invasive plants pose a great threat to the native plants and conservation of biological diversity of Australia, given the high level of endemism [1]. About 29000 non-native plants were introduced to Australia for agricultural production and horticultural acclimitisation [2]. These alien species tend to convert and change ecosystem processes and functions while enabling other invasions [3]. Many of these invaders have become noxious weed [4]. As well as pest [2] the gravity of this problem has now intensified due to climate change [5]. To arrest this weed invasion issue, managers have taken various measures that include legislative and policy framework [1] invasive species management [6], quarantine on the border [2] and chemical and manual control measures on the ground.

\section{Climate Change}

What makes this invasion successful under the climate change regime? Various scientific researches demonstrate that these alien species usually have some unique traits, such as, functional traits, range characteristics, residence time [7-9] and phenotypic plasticity [2]. These traits have helped them to survive and spread out due to anthropogenic climate change. For better understanding [7-9] have conducted a comparative study on 146 pairs of phylogenetically paired neutralized and invasive plant species in Australia introduced almost same time (resident time). They looked at 5 functional traits (flowering duration, leaf size, maximum height, specific leaf area (SLA) and seed mass) and 3 characteristics of the species' natural ranges (biome occupancy, mean annual temperature and rainfall breadth) between the neutralized and invasive species. Study findings showed that alien species have larger SLA, longer flowering periods, and also taller in height than their congeneric neutralized relatives. These species have greater tolerance to various environmental conditions; occupy more biomes and a wider length of rainfall and temperature conditions than naturalized congeners. The important finding of this research was the role of SLA as it is related with faster growth rates, more rapid turnover of leaf material and shorter lifespans facilitating the transformation of a neutralized species to become invader. Having a wider phenotypic plasticity also advances the chances of out-performing the indigenous plants in a disturbed environment $[8,10]$. Further reading of this article suggests that phenotypic plasticity in invaders was related with changes in biomass allocation pattern, physiological responses, circumnutating or germination response to various environmental variances, specifically temperature. For example, another research showed that invaders notably reduced fitness and growth of the resident species by $47.7 \%$ and $22.1 \%$ respectively and also altered the plant community structure by lowering species abundance by $43.5 \%$ and diversity by $50.7 \%$.

A study on invasive species, Acacia nilotica, using CLIMAX model method, suggests that global climatic change is accelerating the species invasion and expand further [11]. This A. nilotica species is well established in Queensland, since its introduction to the country and over the period of time it had spread throughout much of central and western Queensland stipulating nascent foci for further invasion. According to [10] this weed species hampers pasture production, increases soil erosion, obstructs livestock access to water, and increase water loss through transpiration. Researcher Beaumont, et al. [7] found out that increased atmospheric $\mathrm{CO}_{2}$ as a result of climate change, assisting the species to master water use efficiently and exceedingly invading xeric sites further inland. Furthermore, the species using increased temperature to complete its life cycle to invade southward. The research finding also suggested that a climate change induced increase in temperature $\left(2^{\circ} \mathrm{C}\right)$, rainfall and water-use efficiency would assist the species in large-scale expansion in areas with highest growth index. So, this is evident that continuous climatic change is directly assisting poikilothermic species, for instances, the $A$. nilotica to become a true invader in two different ecosystems and threatens the natural setting.

Predictive temperature increase is also linked with increase in bushfire in Australia. Researchers have found a direct link between invasive species coverage and increase bushfire risk [4,5]. For example, invader Gamba grass (Andropogon gayanus) has influenced fire incidents in the tropical savanna ecosystem of northern Australia $[4,5]$. Empirical researches are evident that weed infestation is detrimental to any ecosystem. Weeds have threatened ecosystem constancy and functional complexity, thus extinction of numerous native plant 
species [1]. The invaders compete with the native plants for their growth and survival, such as, light, nutrients, moisture, pollinators and they overpower or swarm the soil. Native plants are badly impacted by this unhealthy competition. This competition for resources halt the natural regeneration process, replace the native plant pools, increase soil erosion by shading out ground plants, landscape changing, degraded water quality and more importantly introduction of foreign genes into native population through cross-breeding [1]. The impact of weed invasion is so severe that one single invasive weed, bituo bush (Chrysanthemoides monilifera), is responsible for population decline of 63 rare and threatened indigenous species of New South Wales states alone [4]. Weed invasion also affect agricultural production under this climate change regime. A study suggests that for agricultural fields, it cause more damage on average of $34 \%$ than the overall agricultural pests [12]. So, it is safe to say that the magnitude of the problem is higher than what has been researched out.

Another study by Williams, et al. [1,3,13] suggests that climate change may foster alien species invasion by reducing resilience of native plants and thus impacting indigenous ecosystem. This may in turn prioritize invaders over indigenous plants regarding vegetation management effectives. They have identified fire drivers that can influence plant assemblages owing to climate change (Figure 1).

These are,

- Changed climate conditions directly affecting species demographic processes such as seed bank persistence, seedling survival, growth rate and reproductive output;

- Changes in competitive interactions between species under changes conditions of $\mathrm{CO}_{2}$, temperature, rainfall, extreme events and disturbance regimes;

- Reduced biomass or increased mortality of individuals in resident communities resulting in the colonization opportunities;

- Changes in interaction between plant species and enemies(pathogens, herbivores, and seed predators) or mutualits (mycorrhiza, pollinators and seed dispersers); and

- Changes in vegetation management regime or effectiveness under climate change.

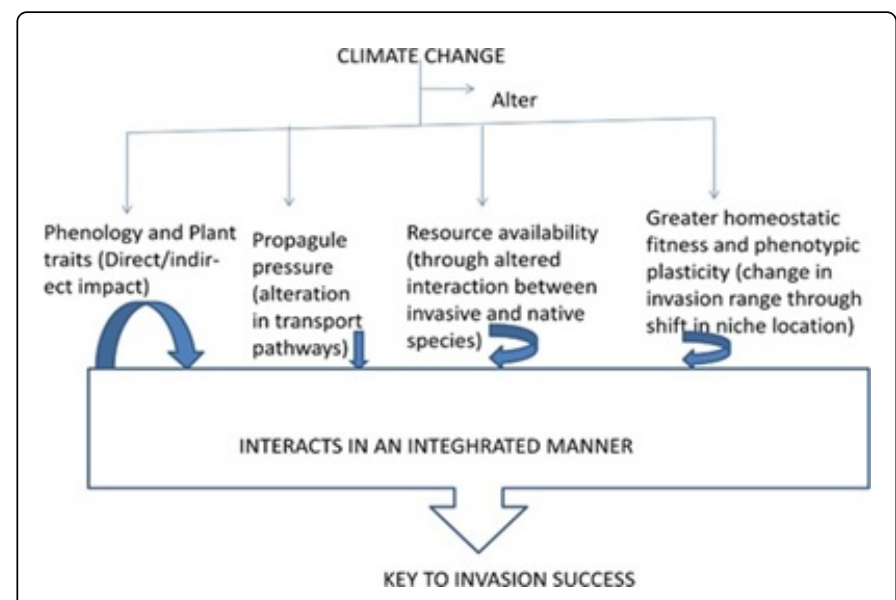

Figure 1: Interlink of attributes are responsible for invasion success under climate change.

Existing research and theories suggests that low species richness areas are more vulnerable to exotic species invasion than the high plant richness areas. It has been argued that high species diversity makes efficient use of the existing resources preventing any invasion in comparison to low-species richness areas-as their inter-specific interactions are rather simple and gaps in exiting resource-use Stohlgren, et al. $[9,11]$ and colleagues conducted research in nine different vegetation types which showed that exotic species cover was positively correlated with mean foliar cover, mean soil Nitrogen percentage and the total number of exotic species. They concluded that exotic species invasion depends on spatial scale, biome, vegetation type, spatial autocorrelation effects, resources availability and speciesspecific responses to grazing and other disturbances and independent of species richness. Another research on exotic annual grass and forbs in California showed that the exotic grass abundance increases with the increase of disturbances like, burning, gopher disturbance and mowing [13].

\section{Current Management Approach}

Current Australia now has standardized its monitoring system on new plant introduction and poses strict control by weed risk assessment (WRA) protocols and quarantine at the border. But researchers have criticized the system, as WRA protocols do not precisely address the effect of changing climate change in the likelihood of species being invasive when introduced to the country [8]. Another criticism on WRA, is it may 'wave through' many species without proper $[9,13]$ investigation on the ability of the species become invasive under climate change regime. They further urge the need of reassessment of bio-control use in managing high-priority weeds, as they fear that many bio-controls may become ineffective in controlling weed population further owing to climate change.

\section{Suggestion}

- A shift in management approaches from control of alien species to building resilience of resident vegetation assemblages [1,3,13].

- Advanced risk management (RA) is must for taxa other than plants and vertebrates [14].

- More emphasis on research on development of strategies to increase resident community resilience to invasion by invaders $[1,3,13]$.

- Further warrant on fundamental ecological research to improve accuracy of predictions of dispersal dynamics and demography of native and non-native species arresting future climatic changes $[1,3,13]$.

- Develop better understanding and strategies to minimize introduction of new species in both agricultural and horticultural sectors $[1,3,13]$.

- Owing to the fact that invasive plant management is complex and requires a network of scientific, bureaucratic, regulatory and technological practices, it arrests the need of a strong and effective infrastructure $[4,5]$.

- To have an effective invasive plant management, activities, like, strategies, declaration and programs, should also be connected with the on-ground engagement [15].

\section{Conclusion}

From above discussion, it has been understood that climate change will favor the growth of invasive weed species over the native species. However, researchers and managers across the globe are trying to find 
Citation: Sultana R (2018) Invasive Plant species (Weed) Challenge in Conservation in Australia. J Biodivers Biopros Dev 5: 172. doi:

Page 3 of 3

out new effective ways to battle weed invasion. Finally, I want to wrap up the essay on a bright note, on-going researches on genetic diversity and phyllo-geographic history of the invasive plants populations may help to develop better understanding of the genetic relationships among invaders [4]. Thereby, improve our understanding for better predictions on how this relationship is going to impact on future spread and better manage invaders possessing potentially diverse biotypes, displaying diverse breeding system, life histories and invasion histories. An effective governance practice is warranted to invasive species through good governance and practice [5].

\section{References}

1. Williams JA, West CJ (2000) Environmental weeds in Australia and New Zealand: issues and approaches to management. Austral Ecology 22: 425-444.

2. Stow A, Maclean N, Holwell GI (2014) Austral Ark. Cambridge University Press, Cambridge and London, UK.

3. Jupiter S, Mangubhai S, Kingsford RT (2014) Conservation of biodiversity in the pacific Islands of Oceania: challenges and opportunities. Pacific Conservation Biology 20: 206-220.

4. Shaik RS, Zhu X, Clements DR, Weston LA (2016) Understanding invasion history and predicting invasive niches using genetic sequencing technology in Australia: case studies from Cucurbitaceae and Boraginaceae. Conservation Physiology 4: 1-13.

5. Head L, Atchhison J (2015) Governing invasive plants: policy and practice in managing the Gamba grass (Andropogon gayanus)-Bushfire nexus in northern Australia. Land Use Policy 47: 225-234.

6. Richardson DM, Pysek P (2012) Naturalization of introduced plants: ecological drivers of biogeographical patterns. New Phytologist 196: 383-396.
7. Beaumont LJ, Gallagher RV, Leishman MR, Hughes L, Downey PO (2014) How can knowledge of the climate niche inform he weed rish assessment process? A case study of Chrysanthemoides monilifera in Australia. Diversity and Distributions 20: 613-625.

8. Seabloom EW, Harpole WS, Reichman OJ, Tilman D (2003) Invasion, competitive dominance, and resource use by exotic and native California grassland species. Proceedings of the National Academy of Sciences 100: 13384-13389.

9. Stohlgren TJ, Binkley D, Chong GW, Kalkhan MA, Schell LD, et al. (1999) Exotic plant species invade hot spots of native plant diversity. Ecological monographs 69: 25-46.

10. Gallagher RV, Randall RP, Leishman MR (2014) Trait differences between naturalized and invasive plant species independent of residence time and phylogeny. Conservation Biology 29: 360-369.

11. Mackey AP (1997) The biology of Australian weeds 29. Acacia niloticassp. indica (Benth.) Brenan. Plant Protection Quarterly 12: 7-17.

12. Daehler CC (2003) Performance comparisons of co-occurrence native and alien invasive plants: implications for conservation and restoration. Annual Review of Ecology, Evolution and Systematics 34: 183-211.

13. Oerke EC (2006) Crop losses to pests. The Journal of Agricultural Science 122: 31-43.

14. Rai PK (2015) Paradigm of plant invasion: multifaceted review on sustainable management. Environ Monit Assess 2015: 187-759.

15. Kriticos DJ, Sutherst RW, Brown JR, Adkins SW, Maywald GF (2003) Climate change and the potential distribution of an invasive alien plant: Acacia niloticassp.indicain Australia. Journal of Applied Ecology 40: 111-124. 